\title{
GESTIÓN DE RESIDUOS LIQUIDOS: ANÁLLISIS DE LA GENERACIÓN DE AVUS, EN RESTAURANTES Y CAFETERÍAS DE LA COMUNA CUATRO DE VILLAVICENCIO (META, COLOMBIA)
}

\section{LIQUID WASTE MANAGEMENT: ANALYSIS OF THE GENERATION OF AVUS, IN RESTAURANTS AND CAFETERIAS OF THE COMUNA CUATRO DE VILLAVICENCIO (META, COLOMBIA)}

\section{Castro Garzón, Hernando ${ }^{1}$}

\section{Ávila Sierra Héctor Manuel²}

Salcedo Parra, Octavio José ${ }^{3}$

\section{RESUMEN}

En el presente artículo se analiza la generación de aceite vegetal usado (AVU) en restaurantes y cafeterías de 30 barrios de la comuna 4 de Villavicencio Meta, y se plantean alternativas para el manejo adecuado y disposición final del residuo, mediante una investigación de tipo

1 Profesor, Escuela de Administración y Negocios. Facultad de Ciencias Económicas, Universidad de los Llanos, Villavicencio, Colombia. Correo electrónico: hcastro@ unillanos.edu.co. ORCID: https://orcid.org/0000-0003-12990489

$2 \quad$ Profesor, programa de Ingeniería Industrial. Universidad Santo Tomas sede Villavicencio, Colombia. Correo electrónico: hectoravila@usantotomas.edu.co. ORCID: https://orcid.org/0000-0003-0278-4219

3 Profesor Titular. Facultad de Ingeniería. Universidad Distrital Francisco José de Caldas. Bogotá, Colombia. Profesor de Planta, Departamento de Ingeniería de Sistemas e Industrial, Universidad Nacional de Colombia, Sede Bogotá. Correo electrónico: octavionetworking@gmail.com ORCID: https://orcid.org/0000-0002-0767-8522 exploratoria-descriptiva, que permite identificar zonas de mayor generación del residuo, formas de conducta frente a la problemática estudiada, cantidad y frecuencia de generación y los hábitos de gestión del residuo, información que fue recolectada con la aplicación de una encuesta semiestructurada compuesta por 18 preguntas.

Los resultados indicaron que existe gran desconocimiento de las alternativas de gestión del residuo, adicional a esto, más del $40 \%$ de las unidades encuestadas son conscientes de los impactos ambientales causados al verter aceites a las fuentes hídricas o los daños a la salud que 
genera reutilizar esta sustancia, por otro lado teniendo en cuenta la visita a la corporación autónoma regional del Meta, y la recolección de información de fuentes secundarias y primarias, se pudo afirmar que existe un conjunto de regulaciones a nivel nacional e internacional que hablan de la importancia del desarrollo sostenible de manera imprecisa o vaga frente a lo que el aceite usado de cocina respecta, pero hace falta en el ámbito local la aplicación del principio para el adecuado manejo del aceite vegetal usado en Colombia, no hay normativa que busque el adecuado manejo del aceite vegetal usado y su potencial concreto como materia prima de otros productos, las alternativas actuales están basadas en las practicas informales de recolectores, no existe una estrategia municipal organizada que este enfocada en la gestión de este residuo peligroso.

\section{PALABRAS CLAVE}

Aceite de cocina, gestión del residuo, impactos 425 ambientales, unidades económicas.

\section{ABSTRACT}

This paper discusses the generation of used vegetable oil (AVU) in restaurants and cafes in 30 neighbourhoods in commune 4 of The Villavicencio Meta, and proposes alternatives for the proper management and final disposal of the waste, through an exploratory-descriptive research, which allows to identify areas of greater waste generation, forms of behavior against the problem studied, quantity and frequency of generation and waste management habits, information that was collected with the application of a semi-structured survey composed of 18 questions.

The results indicate that there is great ignorance of waste management alternatives, an additional addition that more than $40 \%$ of the units surveyed are aware of the environmental impacts caused by pouring oils to water sources or the damage to health caused by reusing this substance, on the other hand taking into account the visit to the regional autonomous corporation of the Meta , and the collection of information from secondary and primary sources, it can be said that there is a set of national and international regulations that speak of the importance of sustainable development in an imprecise or vague way in the face of what used cooking oil refers to, but it is necessary at the local level to apply the principle for the proper management of vegetable oil used in Colombia, there are no regulations that seek the proper management of used vegetable oil and its concrete potential as raw material of other products, the current alternatives are based on the informal practices of collectors, there is no municipal strategy, organized that is focused on the management of this hazardous waste.

\section{KEYWORDS}

Cooking oil, waste management, environmental impacts, economic units

\section{INTRODUCCIÓN}

"Los aceites han sido utilizados por los humanos desde épocas ancestrales como parte fundamental de su alimentación y más recientemente como combustibles" así lo plantea (Agüero et al., 2015), quien refiere además que son claves para la nutrición y para la generación de energía, y en consecuencia son considerados procesos básicos para la supervivencia, pero se debe tener en cuenta que existen diferentes aceites y que según su origen pueden ser, aceites de origen animal, aceites de origen mineral y aceites de origen vegetal, los primeros se obtienen de tejidos animales en los procesos de restitución o extracción, el segundo es un subproducto de la destilación del petróleo. Y, por último, los aceites de origen vegetal, que son un compuesto orgánico que se genera de las semillas $u$ otras partes de las plantas en cuyos tejidos se almacenan como fuente de energía. 
De acuerdo con (Pons, 2015)en los últimos años, aproximadamente a partir de la década del sesenta, los aceites vegetales han adquirido mayor relevancia como resultado de una sociedad que cada día es más exigente y que se ha venido reconociendo la importancia de una buena alimentación, sumado a esto el boom de los estilos de vida saludables y la búsqueda por satisfacer las necesidades energéticas existentes sin provocar acumulaciones dañinas que conllevaran la aparición de enfermedades, es esta una razón para que salieran a los mercados aceites de oliva, maíz, canola, palma, girasol, soja entre otros.

Actualmente los aceites vegetales tienen gran presencia en los hogares y en la industria alimenticia, y una parte importante de estos aceites se utilizan en el proceso de fritura de muchos de los alimentos que consumimos a diario, y como muchos de los productos que hacen parte de nuestro diario vivir, los aceites terminan siendo origen de contaminación, esto debido a que no se ha generado un proceso que permita dirigir los aceites a una disposición final adecuada, es normal evidenciar que se vierten los aceites usados de cocina en los sifones de nuestros lavaplatos, y esto a fin de cuentas finaliza en nuestras fuentes hídricas, por lo tanto, repercute negativamente en el ciclo del agua y en el desarrollo de la vida en los ríos y mares.

Evaluando el contexto anterior el presente trabajo se analizó cuanto aceite vegetal se produce, como se está tratando, que alternativas existen para minimizar el impacto ocasionado por este residuo haciendo una revisión documental del tema a nivel mundial, nacional y regional que permiten que se tenga una imagen más amplia de este fenómeno que se ha ido incrementando con el pasar de los años, además se proponen alternativa de solución viable y sostenible a esta problemática, tomando como referente el concepto de desarrollo sostenible y amigable con el medio ambiente.

\section{CONTEXTO TEÓRICO}

\section{ACEITES Y GRASAS}

Los aceites y grasas son sustancias de origen vegetal $o$ animal que consisten predominantemente en mezclas de esteres de la glicerina con los ácidos grasos, es decir, triglicéridos, de manera más sencilla, el aceite es un material en estado líquido y las grasas se encuentran en un estado sólido, pero no es común que se realice una diferencia marcada entre estos dos factores por lo que en el presente trabajo se mencionan las dos sin que exista diferencia alguna, apuntando a el tipo de aceite en estado líquido. (Bailey, 2001, pág. 4).

Por su lado el Código alimentario de España (CAE), definió el aceite como un tipo de grasa comestible, que puede ser de origen animal o vegetal, compuesto básicamente por glicéridos naturales de los ácidos grasos, y agrega además que el aceite es un líquido oleoso extraído de los frutos maduros del olivo olea europea $L$, Sin que haya sido sometido a manipulación o tratamiento.

En el marco de este análisis, se entiende el aceite como un término que se tiende a utilizar de manera genérica para referirse a numerosos líquidos grasos pues cuentan con características intrínsecas que permite que no se disuelvan en el agua, ya que tienen menor densidad que esta, una de las causas de que su impacto sea altamente negativo cuando se vierte en los lavaplatos de unidades domiciliarias 0 económicas, que puede ser de tipo vegetal y animal, que suelen permanecer en estado líquido. 


\section{ACEITE VEGETAL}

Los aceites vegetales provienen de semillas de girasol, canola, maíz, oliva, coco, palma, aguacate entre otros, actualmente su uso es mayor que el de los aceites de fuente animal, debido a que tienen mayores índices de grasos saludables y menos grasas saturadas.

El aceite vegetal es un compuesto orgánico obtenido a partir de semillas $u$ otras partes de las plantas, está compuesto por lípidos, es decir, ácidos grasos de diferentes tipos. La proporción de estos ácidos grasos y sus diferentes características, son las que dan las propiedades a los distintos aceites vegetales existentes (BUNGE, n.d.)

\section{ACEITE USADO VEGETAL}

Según AMORÒS (2017) el aceite vegetal usado, es aquel aceite que al ser utilizado en frituras ha sufrido procesos térmicos y cambios en sus características originales (organolépticas y fisicoquímicas), y se convierte en un aceite no apto para el consumo humano, por su parte el ingeniero ambiental Villabona (2017) en su artículo "Alternativas para el aprovechamiento integral de residuos grasos de procesos de fritura el aceite usado". El aceite de cocina usado es un residuo urbano proveniente del uso doméstico en la preparación de alimentos, claramente existen muchos tipos de aceites, y según el tipo muchos autores definen las estructuras químicas de cada uno, pero para el desarrollo de la temática del presente trabajo la apreciación de Villabona es la más acorde, ya que sea el tipo de aceite vegetal que sea, el que aquí se va a estudiar es un aceite que ha sido pasado por un proceso de fritura en la utilización de cocción de diferentes alimentos.

\section{FACTORES DE DETERIORO DEL ACEITE VEGETAL USADO}

Los factores de deterioro del aceite usado de cocina varían dependiendo del alimento a freír y de las condiciones del medio ambiente dentro de las condiciones directas a las cuales se exponen los aceites y causan deterioro y oxidación están: a). Período de almacenamiento (comienza tan pronto como es producido el aceite. Durante este tiempo está poco expuesto al aire y se encuentra a temperatura ambiente), b). Período de espera o standby (Son los tiempos necesarios para alcanzar la temperatura de fritura y para el enfriamiento, al finalizar la misma. Durante estos períodos está expuesto al aire a elevadas temperaturas), c). Período de fritura (el aceite está expuesto a altas temperaturas, al aire y al vapor proveniente del agua del alimento que se está friendo). ( Juárez, 2007)

Los aceites sufren cambios químicos que deterioran la calidad del producto y reducen su valor nutritivo, adicional a ello al ser utilizado más de dos veces el aceite produce olores y sabores indeseables en los alimentos freídos en ellos.

Ayala (2011) nutricionista dietista, afirma que este deterioro del aceite depende de varios factores que pueden ser controlables o no controlables, entre estos se conocen: el tipo de proceso o tipo de freído, la relación que existe entre cantidad de alimento y el volumen de aceite la temperatura, la intermitencia entre enfriar y calentar, el grado de instauración del aceite utilizado, el alimento, la luz, el mantenimiento del equipo de freído y el uso de filtros.

Una de las formas de mayor simplicidad que permite identificar cuando un aceite es reutilizado, es el color ya que entre más se fríe va perdiendo sus propiedades naturales y cambia de color, pasando de un amarillo a un marrón oscuro debido al proceso de oxidación de este. 


\section{PROCEDENCIA DEL ACEITE VEGETAL USADO}

Según un informe de la Corporación (CECAN CORPORACION, n.d.), las unidades económicas que más generan aceite de cocina usado y grasas animales son: restaurantes, Cafeterías, Panaderías, Piqueteaderos, Fritanguerías, Negocios ambulantes, Plantas procesadoras, Centros recreacionales, hoteles, hospitales, y centros comerciales.

\begin{abstract}
El ministerio para la transición ecológica y el reto demográfico de España, uno de los países que más adelantado esta en cuanto a prácticas de gestión del residuo de aceite usado, menciona que según datos de la Asociación Nacional de Industriales Envasadores y teniendo en cuenta hábitos de consumo, se estima que pueden generarse unos 150 millones de litros anuales de aceite vegetal usado, procedentes de los siguientes.
\end{abstract}

Tabla 1. Procedencia del aceite vegetal residual

\begin{tabular}{|l|l|}
\hline Domicilios & $\begin{array}{l}\text { Preparación, cocinado y condimento de alimentos en las cocinas } \\
\text { de los hogares. }\end{array}$ \\
\hline $\begin{array}{l}\text { Actividades } \\
\text { Comerciales }\end{array}$ & $\begin{array}{l}\text { Preparación, cocinado y condimento de alimentos en } \\
\text { establecimientos de restauración y hostelería: bares y } \\
\text { restaurantes, hoteles, comedores colectivos de empresas, etc. }\end{array}$ \\
\hline $\begin{array}{l}\text { Administración } \\
\text { pública y } \\
\text { equipamientos }\end{array}$ & $\begin{array}{l}\text { Preparación, cocinado y condimento de alimentos en las cocinas } \\
\text { de centros educativos, comedores sociales, instituciones, etc. }\end{array}$ \\
\hline
\end{tabular}

Fuente: Ministerio para la transición ecológica y el reto demográfico, (2016)

Por su parte (Gobierno de La Rioja, 2016), afirma que el mayor foco de producción de aceites usados de cocina se encuentra en las unidades domiciliarias, que utilizan aceites en la preparación de alimentos, ya que de cada vivienda resulta un subproducto de aceite vegetal usado procedente de freidoras, sartenes, latas, etc. que está muy por encima de la cantidad producida por los establecimientos del sector terciario (freidurías, restaurantes, cattering, etc....)

El presente análisis tomo como objeto de estudio, restaurantes y cafeterías de la comuna cuatro de la ciudad de Villavicencio, muestra representativa de la población total, ya que es uno de los puntos geográficos de la ciudad donde más establecimientos de comida rápida existe, incluso según información entregada por la Cámara de comercio de Villavicencio, la económica de esta comuna se basa en la comercialización de productos alimenticios, en la franja horaria de 4 de la tarde a 12 de la noche.

\section{PROBLEMAS AMBIENTALES RELACIONADOS CON EL INADECUADO MANEJO Y DISPOSICIÓN FINAL DE ACEITE DE COCINA USADO.}

Los aceites de cocina vegetales usados, mal manejados y desechados, generan numerosos problemas ambientales, municipales y de salud, que actualmente son considerados elementos peligrosos, por su persistencia y capacidad de esparcirse en grandes áreas de suelo y agua, además sumado a esto los pocos esfuerzos por generar alternativas desde todos los entes para combatir esta problemática. 
A continuación, se presenta un resumen de los daños generados por los aceites usados de cocina al medio ambiente

Tabla 2. Impactos ambientales del aceite de cocina usado

\begin{tabular}{|c|c|c|}
\hline Impacto en el agua & pacto en el aire & Impacto en el suelo \\
\hline $\begin{array}{l}\text { El aceite usado de cocina } \\
\text { produce una película } \\
\text { impermeable en el agua que } \\
\text { puede asfixiar a los seres vivos } \\
\text { que allí habitan. Un litro de } \\
\text { aceite contamina más de mil } \\
\text { litros de agua. En el mar, el } \\
\text { aceite usado puede perdurar } \\
10 \text { ó } 15 \text { años aproximadamente }\end{array}$ & $\begin{array}{l}\text { Si el aceite vegetal usado se } \\
\text { quema origina importantes } \\
\text { problemas de contaminación } \\
\text { emitidos a la atmósfera. Cinco } \\
\text { litros de aceite quemados } \\
\text { contaminaría } 100.000 \text { m3 } \\
\text { de aire, que es la cantidad } \\
\text { de aire respirada por una } \\
\text { persona durante seis meses } \\
\text { aproximadamente. }\end{array}$ & $\begin{array}{l}\text { El vertido del aceite usado } \\
\text { puede perjudicar tanto el suelo } \\
\text { como las aguas superficiales } \\
\text { y subterráneas, afectando } \\
\text { gravemente a la fertilidad del } \\
\text { suelo, al alterar su actividad } \\
\text { biológica y química. Tan sólo } \\
\text { un litro de aceite usado puede } \\
\text { contaminar una superficie } \\
\text { similar a la de un campo de } \\
\text { fútbol aproximadamente. }\end{array}$ \\
\hline
\end{tabular}

Fuente: (BIOGRAS, 2018)

\section{AFECCIONES DEL ACEITE VEGETAL USADO EN LAS REDES DE} ALCANTARILLADO Y SANEAMIENTO.

Los aceites y grasas unidos a los restos de los detergentes y jabones de uso doméstico provocan en los colectores velocidades bajas (poca pendiente, quiebros, necesidad de constantes bombeos), así como en los desagües generales de las viviendas, las denominadas 'bolas de grasa' son capaces de causar atascos en colectores y elementos anexos, roturas y puestas en carga de los mismos, además, dificultan el intercambio gaseoso entre agua residual y aire en contacto aumentando la progresiva anoxia (falta o disminución de oxígeno) del agua residual a lo largo de los colectores, por lo que aquella llega a las plantas de tratamiento de aguas residuales con mínimos contenidos en oxígeno.

El principal problema de hacer un mal uso del aceite que ya ha sido utilizado reside en la contaminación de las aguas residuales urbanas. La grasa, debido a su característica aglutinante, genera una especie de bolos que producen importantes atascos en las cabeceras de las canalizaciones de la red de aguas residuales, ocasionando desbordamientos. Estos bioresiduos se convierten en caldo de cultivo para la multiplicación de gérmenes que inciden negativamente en la salud de la población. (Wisman, 2018)

Las personas están haciendo el mal uso del aceite usado o quemado debido a que no tienen el conocimiento que existen empresas que se dedican a recoger y trasformar el aceite usado en materias de segunda mano, el cual afecta en alcantarillado y saneamientos cuando las personas agregan los incrementos y lo que hace es que se vuelva una grasa y tape los orificios el cual provoca taponamiento y desbordamiento de agua.

\section{EFECTOS DEL ACEITE VEGETAL USADO SOBRE LA SALUD HUMANA}

Utilizar un mismo aceite, una y otra vez para freír los distintos alimentos es una práctica muy común, sobre todo con el aceite de oliva, cuyo precio resulta bastante elevado y supone una parte importante del gasto en alimentación. Pero 
en realidad, esta es una práctica que no debería realizarse, porque es un hábito poco saludable que puede resultar perjudicial para la salud. Reutilizar el aceite, intentando sacar el máximo partido del 'oro líquido' y de paso ahorrar algo en el carrito de las compras, realmente no compensa

Las altas temperaturas de la cocción alteran las buenas propiedades de cualquier aceite, ya sea de oliva, de girasol u otras semillas. Aunque el de oliva es el que se mantiene inalterable por más tiempo, cocinar con el mismo más de dos veces no es recomendable. (Wisman, 2018)

\section{RESIDUO}

Para (Solarte Burbano \& Vargas Doraro, 2013) los residuos con todos los productos que conocemos actualmente de cualquier tipo, que después ser utilizado y de no encontrarle ya más utilidad o no encontrarle ningún valor, se desecha pero también lo expone como un elemento que aun después de ser utilizado para determinado fin, puede seguir siendo útil para otro, por lo que puede ser reutilizado en lugar de ser desechado, esta última definición es la apropiada y tomada para el presente trabajo, ya que lo que se busca es cambiar el paradigma capitalista que a lo largo del tiempo se nos ha ido creando en la cabeza, y es que lo que pasa de moda de desecha, lo que sufre algún daño se bota, pero no se analiza que pasa con todos los productos que desechamos y el daño que esto está causando al planeta, es crear hábitos que permitan que nuestra huella ecológica sea cada día menor

\section{GESTIÓN DEL RESIDUO}

Aunque la gestión de residuos es un tema contemporáneo, de que mucho se escucha hablar y que ha tomado gran relevancia, existen muy pocas bases teóricas que defina como tal la gestión de los residuos, la Universidad Industrial de Santander (UIS, 2010) en una recopilación de información sobre el tema, determina que la gestión de residuos es el conjunto de actividades encaminadas a dar a los residuos el destino final más adecuado. Por otro lado, (Rondón et al., 2016) , en su guía para la gestión de residuos sólidos domiciliarios, menciona que la gestión de residuos como enfoque, busca "Transformar la cultura actual de eliminación de desechos a una que evite los residuos mediante prácticas de producción y consumo sostenibles." y en ese sentido este trabajo busca que se realice la gestión apropiada, de los residuos de aceite vegetal usados en las cocinas, y pensar que, si es necesario y básico para la producción de alimentos, a corto plazo la cantidad de generación de este va a requerir que se plantee un plan de acción que permita seguirlo utilizando, pero dándole una disposición final adecuada, o sirva como insumo de nuevos productos.

\section{FASES RECOMENDADAS PARA LA GESTIÓN DEL ACEITE VEGETAL RESIDUAL.}

El proceso de recolección de aceites de cocina es sencillo, ya que el generador de este residuo lo único que debe asegurar es que se recolecte el aceite, en envases limpios que no se mezclen con otras sustancias y debe ser entregado filtrado evitando que contenga partículas, seguido a esto debe establecer contacto con empresas que cuenten con permiso para la gestión de este residuo

\section{ALTERNATIVAS PARA LA GESTIÓN DEL RESIDUO}

A continuación se presentan las alternativas que presentan mayor rentabilidad y que a partir del 2018 con la resolución 0316 y teniendo en cuenta que a partir del 1 de enero de 2020 empezara a estar vigente, se abre un oportunidad de negocio aun mayor, ya que será obligación de los generadores de aceites usados contratar una empresa autorizada por la entidad ambiental competente para su gestión y tratamiento final, por lo que ya existe 
mayor viabilidad, y factibilidad de contar con los proveedores y las cantidades necesarias para poder desarrollar industrias a partir de los aceites usados de cocina.

\section{JABONES DE TOCADOR, LÍQUIDOS O EN BARRA NATURALES A BASE DE ACEITE USADO DE COCINA:}

El jabón de tocador es un producto de primera necesidad, es de uso cotidiano y por los menos una vez al día lo empleamos en nuestras rutinas de aseo además es considerado un producto para cuidado de la salud de la piel, al cual se le hace bastante publicidad a través de campañas donde por ejemplo se promueve el lavado de las manos y otros, y es esta una de las razones por las cuales tienen gran participación en los mercados.

Según un informe del OEC (complexity)los principales países exportadores de Jabones son Malasia, (260 millones), indonesia (247

431 millones), Alemania (123 millones), los Estados Unidos (122 millones), e Italia con (105 millones) además también presenta cifras de los mayores importadores de la siguiente manera, Francia en primer lugar (\$110 millones), los Estados Unidos (\$102 millones), China (82.1 millones), Filipinas (70.3 millones) y Reino Unido (\$ 62.1 millones).

En Colombia existen diferentes tipos de marcas de jabón que son muy fuertes, pero la mayoría son industriales, aunque el mercado de jabones artesanales ha aumentado aún hace falta que se logre la alta calidad para que pueda competir con las grandes marcas, además se hace necesario que junto con la comercialización de este tipo de productos se implementen campañas de mercadotecnia que den a conocer toda la cadena de valor, ya que en el contexto actual, las marcas ambientalmente amigables tienen un valor agregado y logran recordación de marca.

\section{BIODIESEL A PARTIR DEL ACEITE USADO DE COCINA}

El biodiesel representa una alternativa para la disposición de aceites usados, pues actualmente se cuentan con técnicas para su conversión y aprovechamiento como combustible, sin embargo, se debe trabajar en el sistema de identificación y recogida de estos residuos, pues representan un reto logístico debido a sus cantidades.

En Colombia a gran escala se producen dos tipos de biocombustibles, Etanol de caña de azúcar y de yuca y Biodiesel de aceite de palma, aun no se produce en grandes márgenes a base de aceites vegetales usados, los precios del biodiesel tuvieron una subida de gran magnitud en el 2019, pero siempre se presenta por encima del diésel

\section{OTRAS ALTERNATIVAS}

- $\quad$ Elaboración de Velas Caseras

- $\quad$ Elaboración de Cremas Corporales

- Utilizarlo como exfoliante combinándolo con otros productos.

- $\quad$ Barro de perforación

- Fabricación de grasas lubricantes secadores metálicos

- Grasa para lubricar la maquinaria empleada en la producción de comestibles

- $\quad$ Grasa para engrasar moldes y equipos de fabricación de pan

- Grasas para la protección de tanques, tuberías o similares, que operan al descubierto 


\section{MATERIALES Y MÉTODOS}

El método aplicado, en este manuscrito es del orden descriptivo, dado que analiza elementos particulares al todo como universo de elementos transversales, desde la observación real del fenómeno, y la utilización complementada con el análisis del mismo. Según el alcance y análisis de los resultados, se considera como descriptivo, dado que, se describen de manera significativa algunas características del fenómeno homogéneo. Además, se aplicó la técnica de investigación, estudio de caso, el cual se caracteriza en un análisis sistemático de un proceso o asunto científico de interés, en condiciones de un fenómeno homogéneo o situaciones que merecen un interés de aplicación, concreta y precisa, según la temática y el objeto de estudio a analizar. Se espera, que las soluciones encontradas al planteamiento inicial, tenga una posibilidad de resultados de investigación más precisos y concisos, sirviendo como fuente secundaria para otros investigadores, y descriptiva por que busca delimitar el problema a través de instrumentos que arrojen datos como número de población, uso por edades, nivel de educación, nivel socioeconómico, entre otros.

Además, identifica formas de conducta, preferencias sobre una marca y otra, que permita conocer las actitudes de las personas que están dentro del universo de la investigación, a través de un método cuantitativo, utilizando encuestas estructuradas.

Para la selección de la muestra de las unidades económicas objeto de estudio, se utilizó un muestreo aleatorio simple donde se realizó una lista numerada de los barrios que hacen parte de la comuna 4, y se tira con unos dados al azar para escoger los barrios en los que realizo el trabajo de campo.
Como instrumento de recolección de datos primarios se diseñó un cuestionario compuesto por 18 preguntas, 6 de tipo cerrada y 12 de tipo abiertas, estructuradas para recopilar información del establecimiento, prácticas de disposición del aceite usado de cocina, valor comercial del aceite usado de cocina y conocimiento de la problemática ambiental que representa este último, adicional se incluyó una pregunta de tipo cerrada, sobre la normatividad de vigente para determinar si se tiene conocimiento, todos estos aspectos informativos necesarios para definir el contexto actual, las encuestas realizadas a las unidades económicas se llevaron a cabo en el mes de febrero de 2020, y fue necesario informar a cada una sobre la temática de las mismas

La encuesta se aplicó al propietario, administradores de establecimiento, o quien hiciera sus veces, en 85 unidades económicas clasificadas con el código CIIU sea 5500 que hace referencia a restaurantes y cafeterías.

\section{RESULTADOS}

Como resultado de la recopilación de información primaria se logró realizar 85 encuestas en 30 barrios, una muestra representativa que permite determinar a grandes rasgos el contexto actual del uso y disposición final de los aceites usados de cocina en la comuna 4 de la ciudad de Villavicencio. 
Ilustración 1. Actividades económicas establecimientos encuestados

\begin{tabular}{|l}
\multicolumn{7}{|c|}{ Actividad Económica } \\
\begin{tabular}{|llc|c|c|c|}
\hline \multirow{2}{*}{ Válido } & Frecuencia & Porcentaje & $\begin{array}{c}\text { Porcentaje } \\
\text { válido }\end{array}$ & $\begin{array}{c}\text { Porcentaje } \\
\text { acumulado }\end{array}$ \\
\cline { 2 - 6 } & Restaurante & 39 & 45,9 & 45,9 & 45,9 \\
\cline { 2 - 6 } & Cafeterías & 46 & 54,1 & 54,1 & 100,0 \\
\cline { 2 - 6 } & Total & 85 & 100,0 & 100,0 & \\
\hline
\end{tabular}
\end{tabular}

Fuente: Autor

Con base en lo anterior a continuación se muestran los resultados de las preguntas más relevantes de las encuestas aplicadas a 39 restaurantes y 46 cafeterías para el presente análisis.

Ilustración 2. Numero de colaboradores de los establecimientos encuestados.

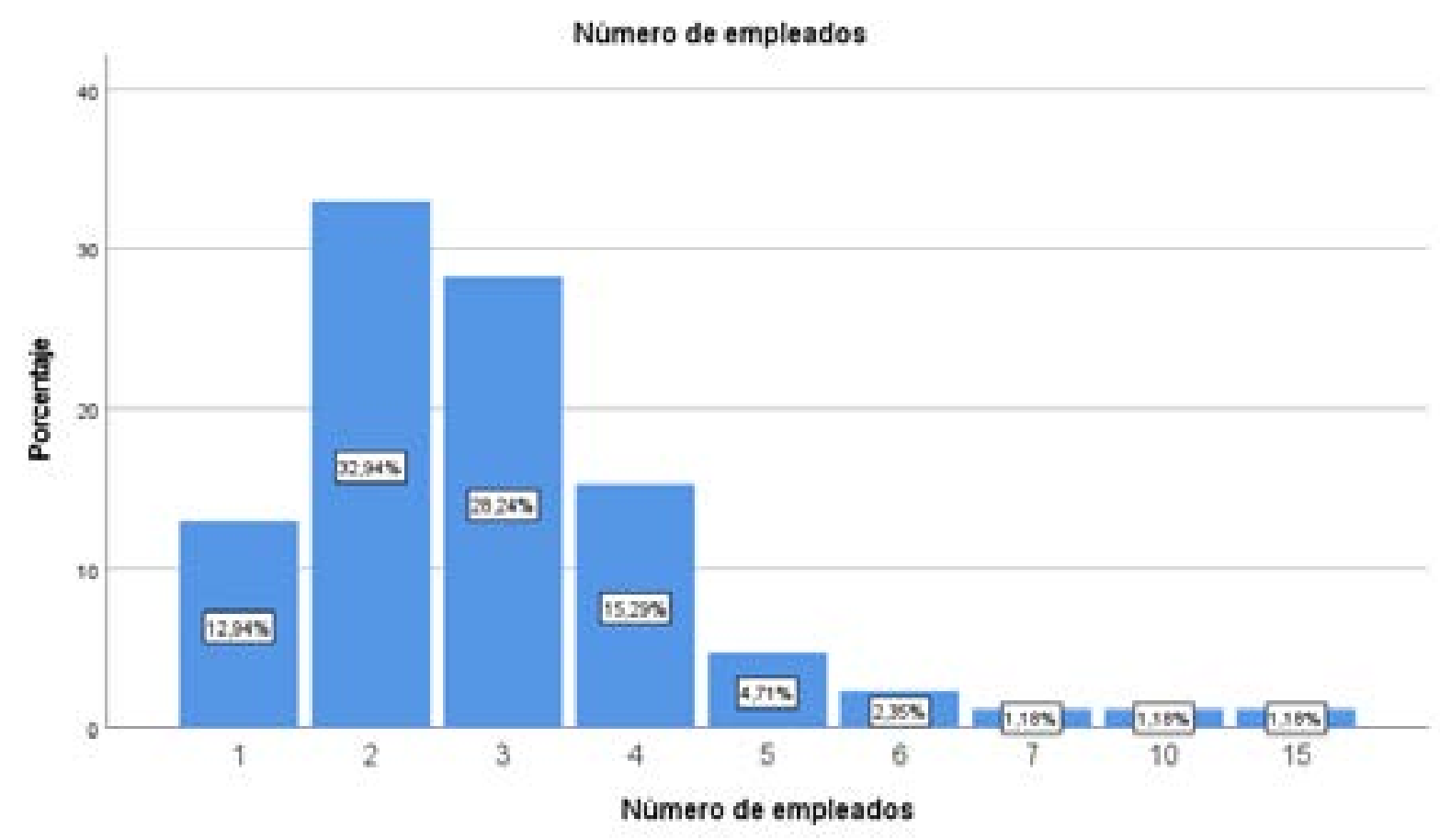

Fuente: Autor

Se tiene que el $32,94 \%$ del total de unidades económicas encuestadas cuenta con dos empleados, el menos porcentaje se encuentran con $1,18 \%$ establecimientos que cuentan con entre 10 y 15 empleados, esta tendencia se debe a que el $54,1 \%$ de establecimientos encuestados fueron cafeterías, que son administradas por sus propietarios y cuenta con algún familiar o en su defecto colaborador 
Ilustración 3. Porcentaje de encuestados por los 30 barrio seleccionados

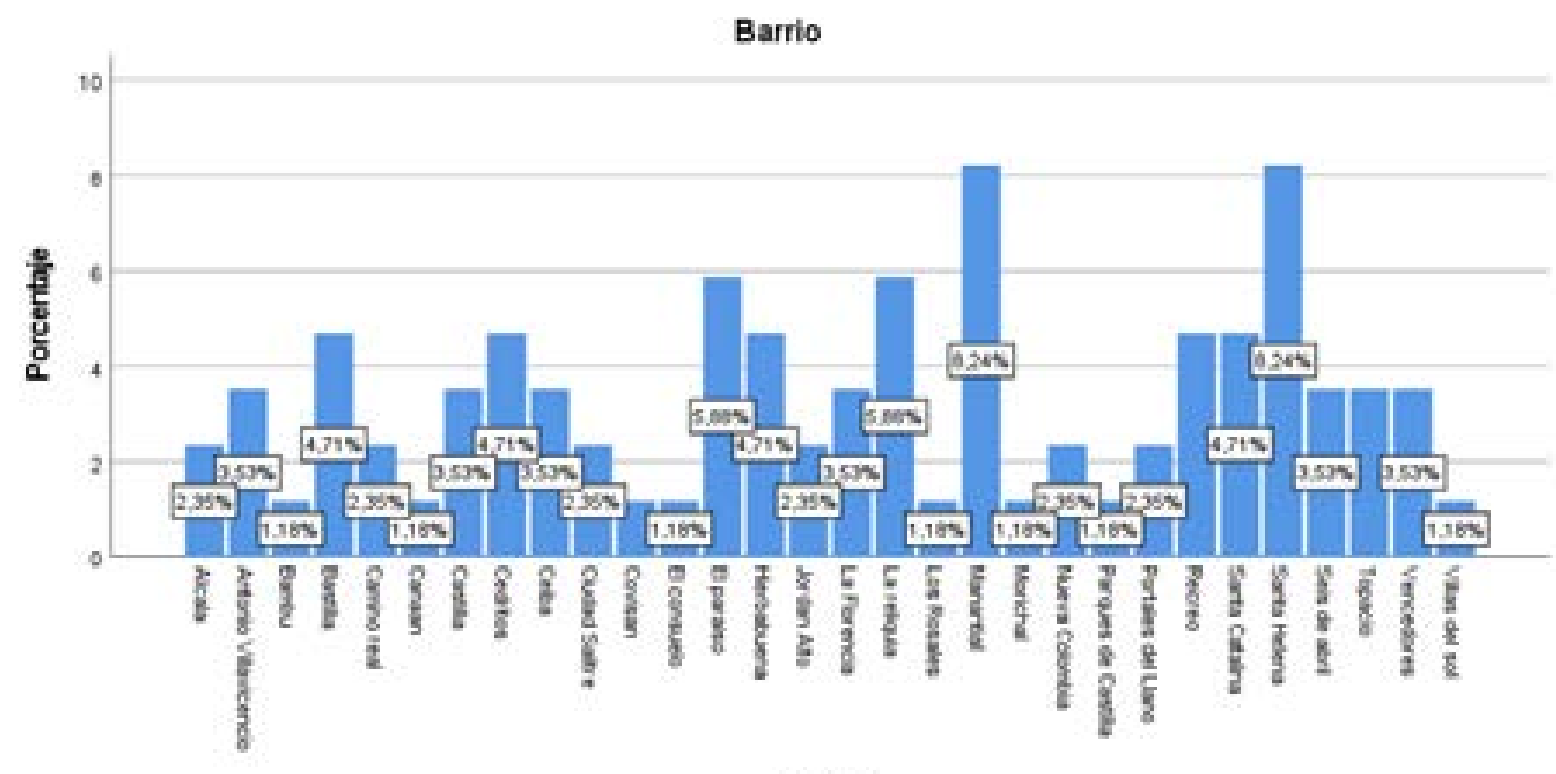

Barrio

Fuente: Autor

De los treinta barrios encuestados, el barrio Manantial y Santa helena son los de mayor representación, esto se debe a que como la encuesta se aplicó en la unidades económicas con el consentimiento de los propietarios, no se contó con la disposición de algunos de ellos, adicional a ello se presenta en algunos barrios problemas de seguridad, y en el caso del barrio santa helena es uno de los barrios con mayor número de unidades económicas de la comuna cuatro, con mejor ubicación geográfica.

\section{Ilustración 4. Litros de aceite utilizados al mes}

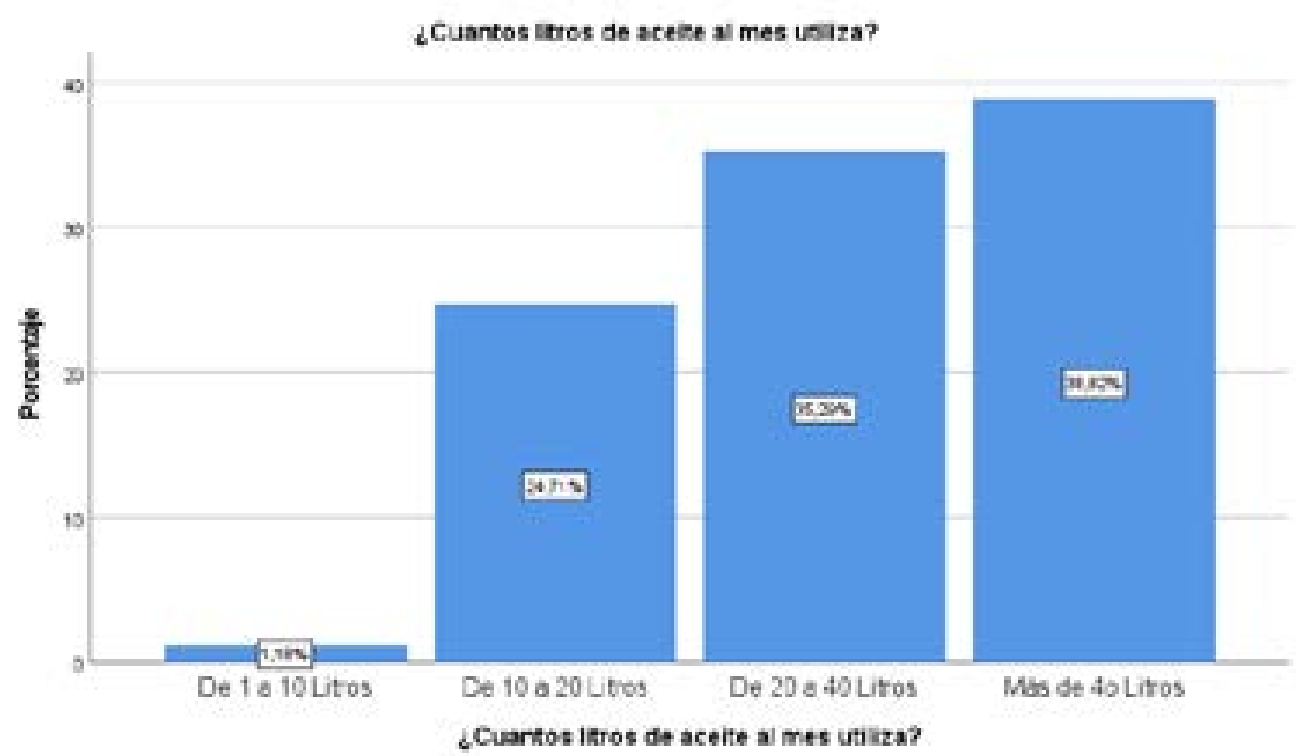

Fuente: Autor 
El consumo mensual de más del $50 \%$ de las unidades económicas analizadas utilizan entre 20 litros y más de 40 litros al mes, y solamente un $1,18 \%$ utilizan de 1 a 10 litros, esto tiene relación según lo observado con el tamaño del establecimiento y las ventas generadas, además se evidencia también que según el tipo de disposición los litros de aceite utilizados tienden a disminuir o aumentar.

\section{Ilustración 5. Porcentaje de encuestados por estrato}

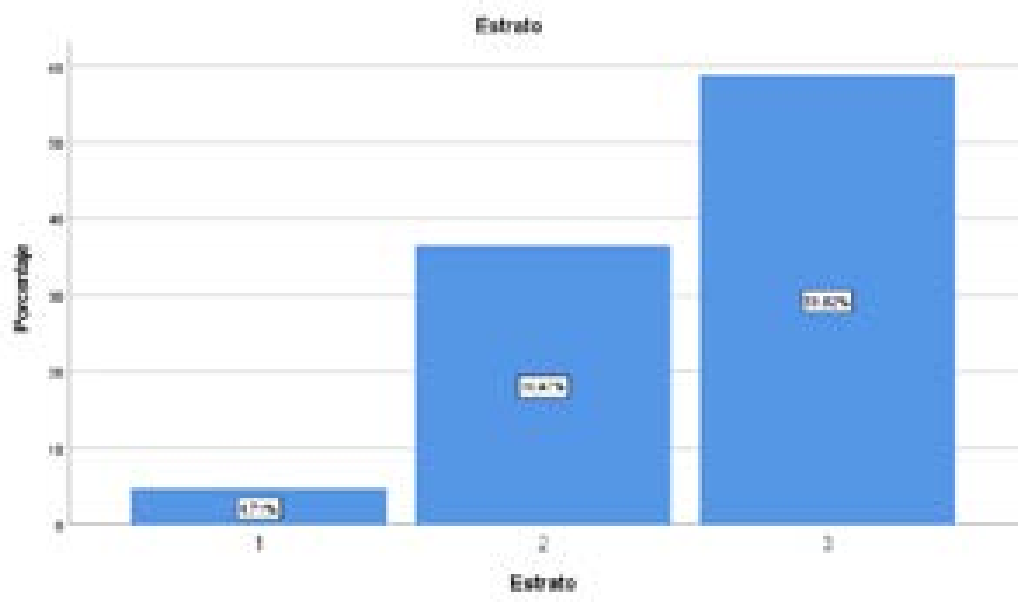

Fuente: Autor

Más del $50 \%$ de los encuestados pertenecen al estrato 3 y solo un $4,71 \%$, pertenecen al estrato 1 , no se cuenta con participación de estratos 4,5 y 6.

\section{Ilustración 6. tipo de aceite}

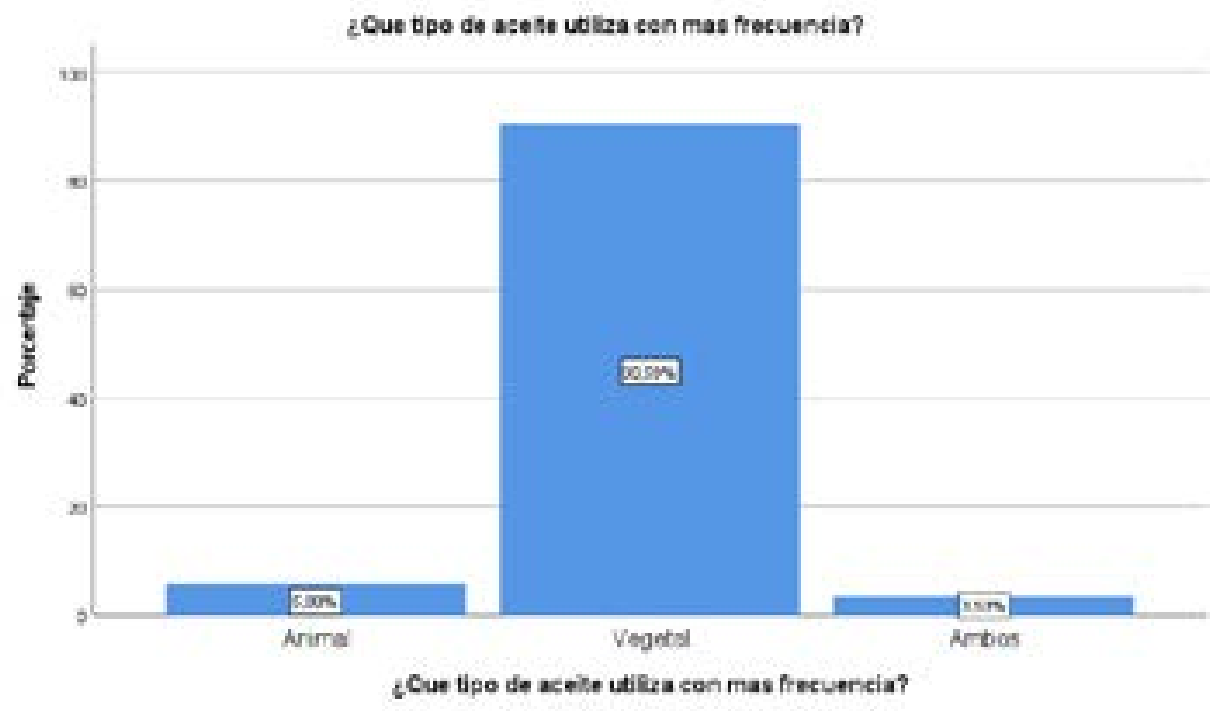

Fuente: Autor 
Del total de unidades económicas encuestadas, se tiene que el $90,59 \%$ utilizan aceite vegetal de cocina, además se encontró que actualmente con el propósito de aumentar la vida útil del producto, se está utilizando un aceite vegetal hidrogenado, que permite que el aceite sea expuesto a altas temperaturas, aumentando la estabilidad oxidativa del aceite, básicamente no se quema o deteriora por lo que no se cambia.

El $5,88 \%$ pertenece a cafeterías y restaurantes que producen y venden productos como:

Churros, Buñuelos, pan entre otros, y el

$3,53 \%$ son pequeños negocios de venta de empanadas y productos de esta misma línea.

\section{Ilustración 7. Realización de encuesta según la separación de residuos de aceite por establecimiento.}

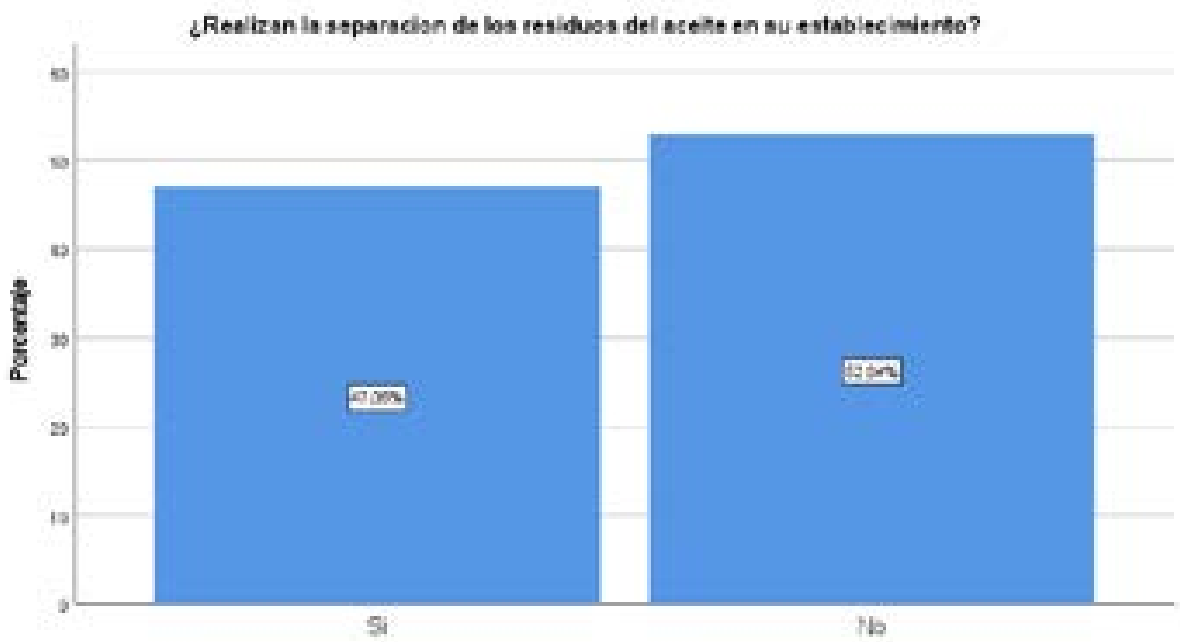

URnaizen is separteion de los residuos dol acoite on au entablecimiento?

Fuente: Autor

Del total de establecimientos encuestados, el $52,94 \%$ no realiza una separación de los residuos del aceite, y el otro $47,06 \%$ si realiza este proceso, pero más adelante se puede evidenciar que el problema radica con la disposición final y la falta de programas de recolección e información de los entes competentes. 
Ilustración 8. descripción de la disposición final del aceite.

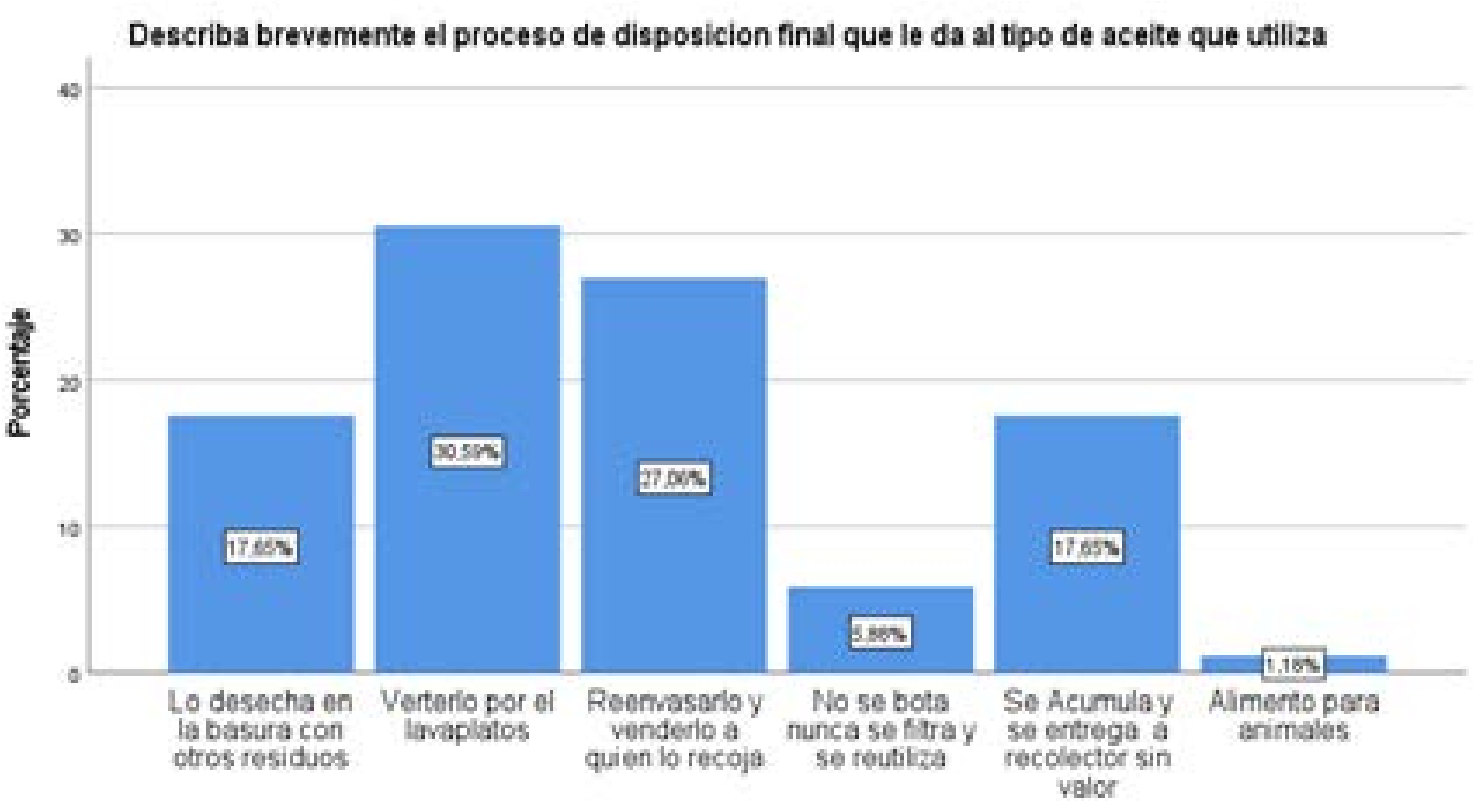

Describa brevemente el proceso de disposicion final que le da al tipo de aceite que utliliza

Fuente: Autor

Del total de unidades económicas encuestadas se encontró que el $30,59 \%$ vierte por el lavaplatos los residuos del aceite de cocina usado, un $17,65 \%$ lo desecha junto con otros residuos por lo que el proceso de separación se pierde, un $5,88 \%$ reutiliza el aceite y en este punto se debe mencionar que esta no es una alternativa viable para realizar la disposición final de este producto ya que ocasiona graves daños a la salud, dentro de los usos adecuados para la disposición final se encuentra venderlo a entidades registradas en las Corporaciones Autónomas Regionales, como recolectores o gestores, del total de encuestados el $27,06 \%$ realiza este proceso.

Ilustración 9. Reconocimiento de programas o formas de disposición final para el aceite.

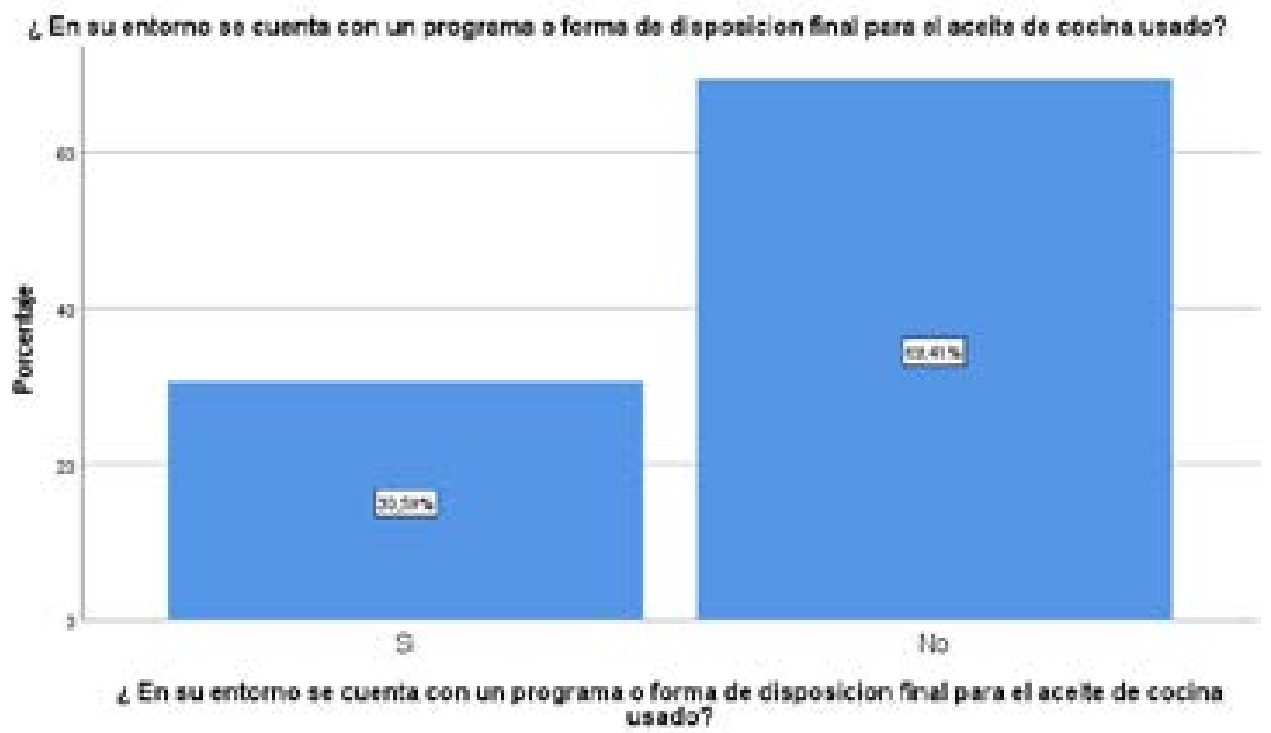

Fuente: Autor 
Se evidencia que el $69,41 \%$ de las unidades económicas encuestadas afirma no conocer programas o formas de disposición final para el aceite de cocina usado, esto se debe a que según lo informado por Cormacarena actualmente por parte de esta entidad ni de ninguna otra gubernamental se están desarrollando programas sobre aceite usado de cocina, ni en unidades domiciliarias, ni en unidades económicas ya que hasta este año entro en vigor la resolución que regula este tema.

Ilustración 10. Descripción del reconocimiento de la resolución 0316 de 2018.

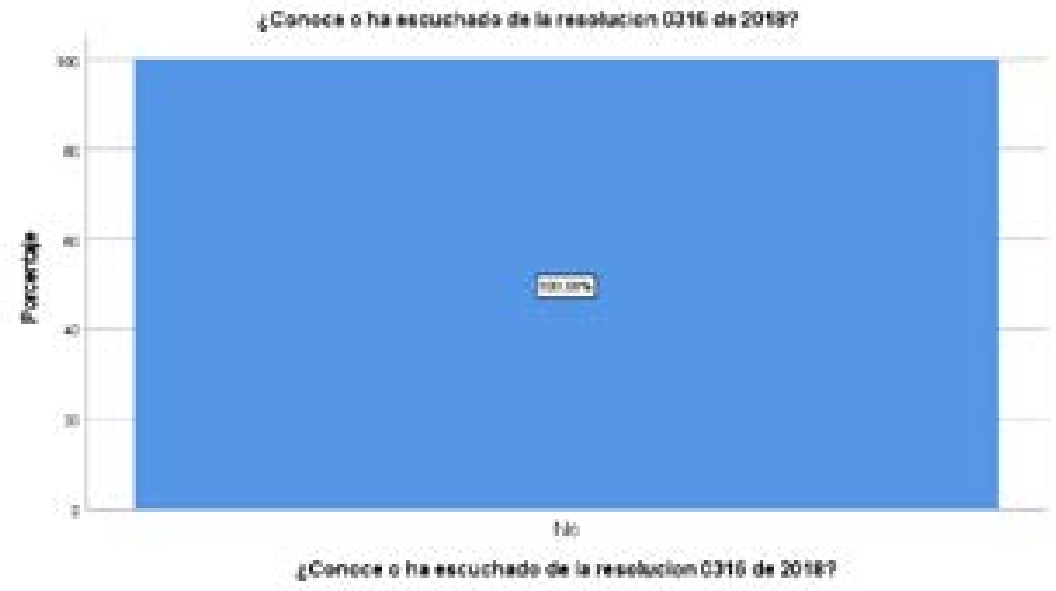

Fuente: Autor

De total de unidades económicas encuestadas, el $100 \%$ desconoce la resolución 0316 del 2018 , aun cuando se les explico de que se trataba y cuando entro en vigencia, las personas afirman que no se ha realizado ningún programa, campaña o relacionado sobre este tema, cuestión que es de suma preocupación teniendo en cuenta que el alcance de la resolución es tanto para gestores como para toda persona que utilice aceite sea para el desarrollo de actividades económicas o para uso doméstico.

\section{Ilustración 11. Encuesta social sobre el conocimiento del tipo de productos que son hechos a base de aceite de cocina usado.}

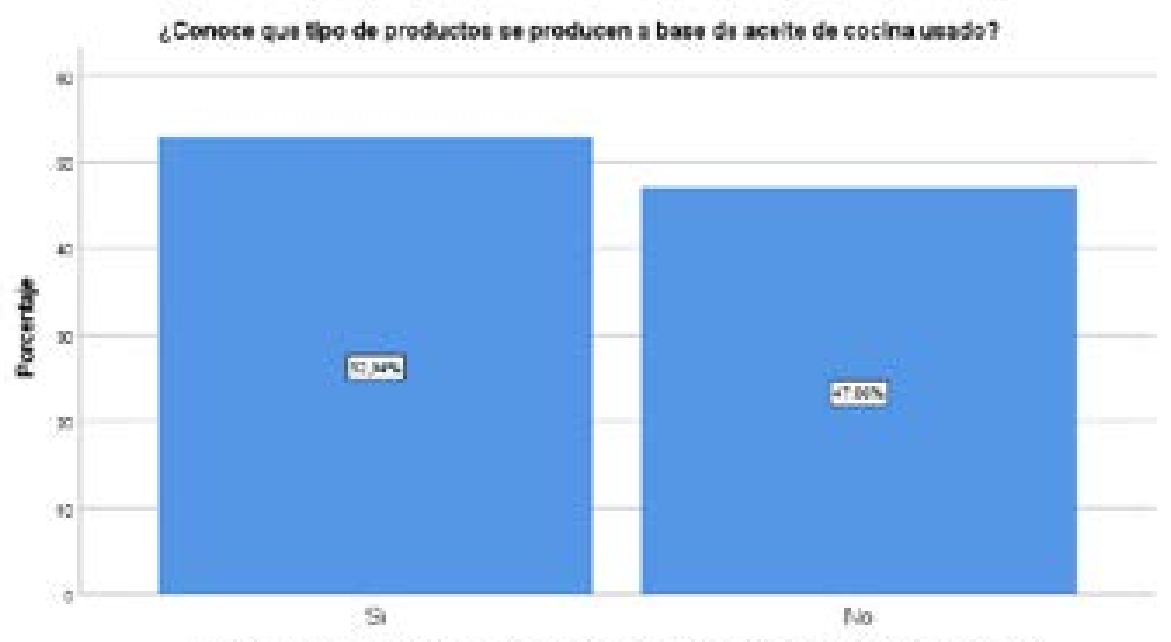

¿Conose que Epo de prosuctos se producen a base de acsite de socha usade?

Fuente: Autor 
Del total de los encuestados el $47,06 \%$ afirma no conocer qué tipo de productos se producen a base de aceite usado de cocina, más adelante se analizará la existencia de relación con los procesos de disposición de este residuo.

\section{Ilustración 12. Reconocimiento social de los daños ambientales que produce el aceite de cocina al no depositarlos en el lugar adecuado (fregaderos)}

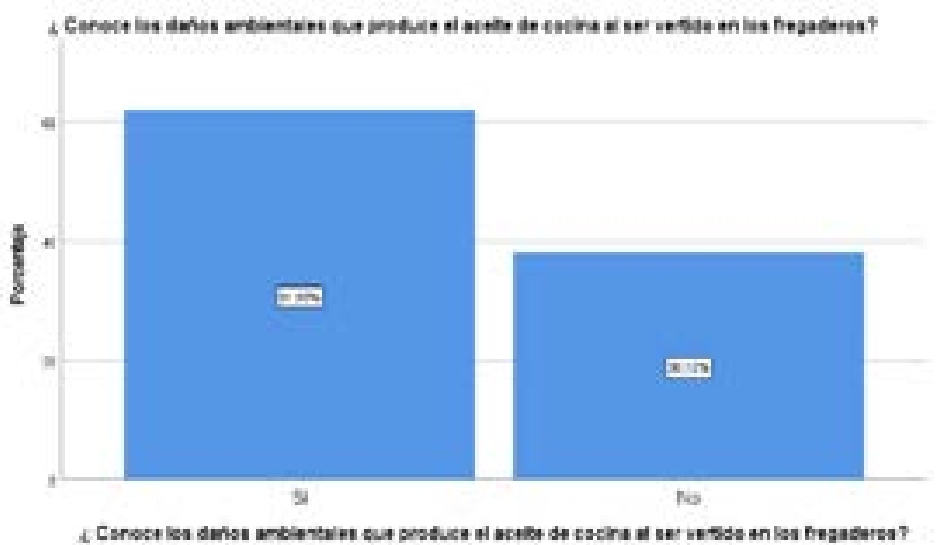

Fuente: Autor

El $61,90 \%$ de los encuestados afirma conocer

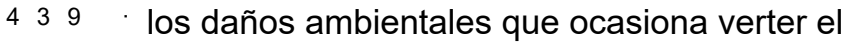
aceite usado de cocina en los fregaderos, pero aun así los porcentajes de uso de esta práctica son del 30,59\%.

Ilustración 13. unidades económicas que presentan mayor consumo de aceite usado de cocina

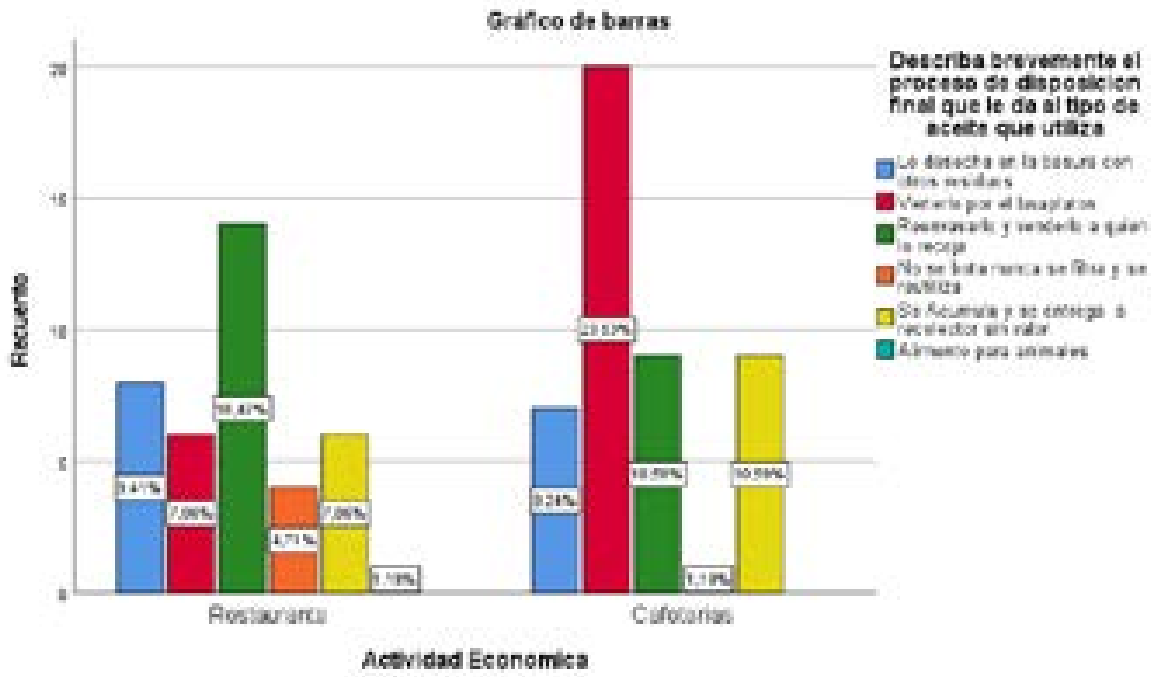

Fuente: Autor 
Las unidades económicas que presentan mayor consumo de aceite usado de cocina son los restaurantes, con un $22,35 \%$ esto se puede deber al nivel de ventas y el tipo de productos que ofrezcan cada negocio.

Ilustración 14. Descripción del proceso de disposición final del aceite tanto en los restaurantes como en las cafeterías.

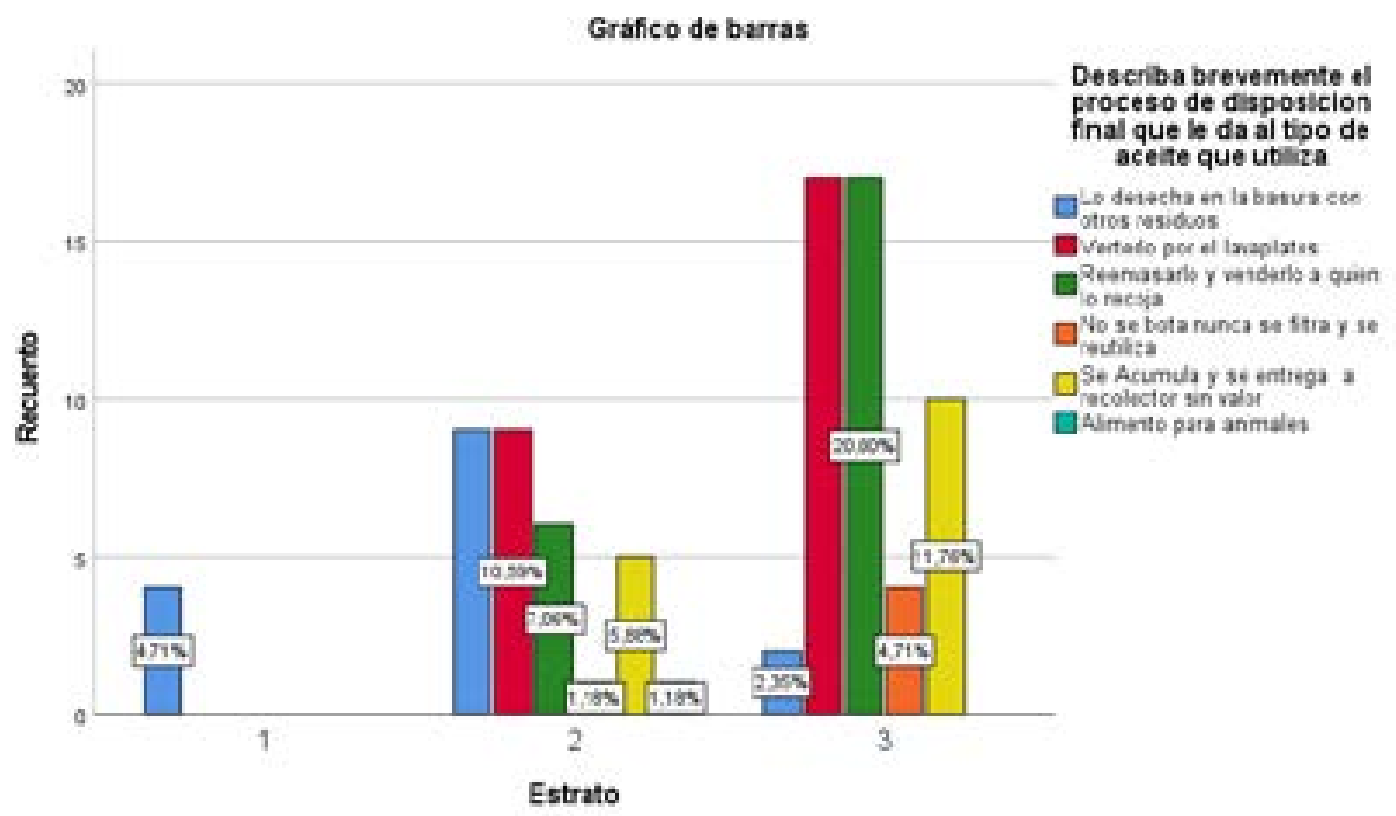

Fuente: Autor

El 23,53\% de las cafeterías del presente estudio, desechan los residuos de aceite usado de cocina por el fregadero, y también representan la mayor cantidad de unidades económicas, por lo que se entiende que el foco para el presente análisis son las cafeterías ya que son las que mayor tendencia tienen de realizar vertimiento de este tipo de residuos.

Ilustración 15. Conocimiento de los daños ambientales que produce el aceite de cocina vertido en los fregaderos

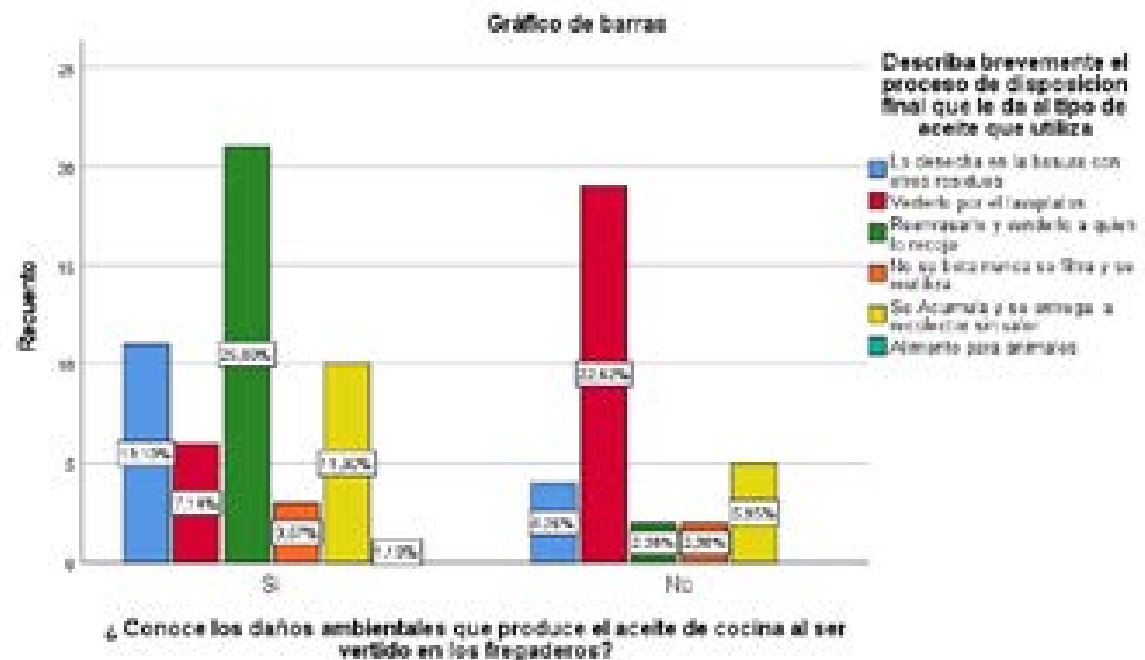

Fuente: Autor 
El $7,14 \%$ de encuestados, aunque conoce los daños ambientales que produce el aceite vegetal al ser vertido en los fregaderos, hace uso de esta práctica, lo que se entiende como un problema de cultura ciudadana y la necesidad de fortalecerla, ya que un $22,62 \%$ de los que vierten los residuos de aceite de cocina usado afirma desconocer los daños que esta práctica ocasiona al medio ambiente.

\section{CONCLUSIONES}

Con el análisis realizado se pudo evidenciar que aunque los porcentajes de establecimientos que realizan proceso de disposición que no benefician al medio ambiente no están en niveles críticos, si marcan una problemática que poco a poco contamina y de la cual no se tiene mucho conocimiento, adicional a esto se percibe que no existe mayor control y seguimiento por parte de entidades estatales, en los procesos de disposición que se les está dando a este tipo de residuos, ya que como se mencionó a lo largo del presente trabajo este año ya entro en vigencia la resolución 0316 que regula la gestión de los aceites de cocina usados y ninguno de los establecimientos tiene conocimiento de la existencia de la misma.

En la ciudad de Villavicencio solo se encuentran tres entidades autorizadas por parte de la CAR para el transporte de aceite de cocina usado, pero en el desarrollo de la investigación se conoció que también existen recolectores informales que no cuentan con ningún tipo de permiso de CORMACARENA para realizar la disposición final de este residuo, que en muchos casos es filtrado y llevado nuevamente al mercado a menor precio y como un tipo de manteca solidificada que se utiliza para diferentes tipos de productos fritos.

Por otro lado, es de suma importancia mencionar que, debido a la poca regulación y control, muchas de las unidades económicas que utilizan aceite para preparar sus productos, lo reutilizan en la fritura de otros alimentos, y esto sin lugar a dudas conlleva a una problemática de salud pública, que hace necesario que se analice y se propongan alternativas que cumplan con los estándares de calidad y salubridad óptimo para el consumo humano.

Claramente lo que se puede concluir es que existe un problema tanto cultural, ético, gubernamental y que les compete a todos entrar a dar soluciones que sean viables, y un seguimiento y control por que el mayor problema que se evidencia es la no existencia de programas, y por ende la desinformación sobre el tema.

\section{AGRADECIMIENTOS}

Los autores de manera especial, reconocen de manera especial a Nelson Javier Amórtegui, Linda Liseth Villanueva, Claudia Daniela Ladino, quienes realizaron el trabajo de campo del presente trabajo, y contacto con la comunidad intervenida, así como a la Universidad de los Llanos (Villavicencio, Colombia), por el apoyo especial en el desarrollo de la investigación.

\section{REFERENCIAS BIBLIOGRÁFICAS}

Agüero, S. D., García, J.T., \& catalán, J. S. (2015). Aceites vegetales de uso frecuente en Sudamérica: características y propiedades. Nutrición Hospitalaria, 32(1), 1119.https://doi.org/10.3305/ nh.2015.32.1.8874

BIOGRAS. (2018). BIOGRAS S.A.S - Aceite Vegetal Usado. Pagina Web. https:// biogras.com.co/avu/aceite-vegetal-usado/

BUNGE. (n.d.). Aceites Vegetales. Pagina Web . Retrieved March 13, 2021, from https:// es.bungenorthamerica.com/products/ categories/96-aceites-vegetales 
CECAN CORPORACION. (n.d.). Biopravu Corporación CECAN. Retrieved March 13, 2021, from https://corporacioncecan.org/ biopravu/

Gobierno de La Rioja. (2016). Aceite usado de origen doméstico. Residuos Con Gestión Especial . https://www.larioja.org/medioambiente/es/residuos/residuos-gestionespecial/aceite-usado-origen-domestico

Juárez, M. D., \& Sammán, N. (2007). El deterioro de los aceites durante la fritura - Dialnet.

Pons, G. A. (2015). Aceites vegetales, hacia una producción sostenible. El Hombre y La Maquina, 46, 9-19. https://www.redalyc. org/pdf/478/47843368002.pdf

Rondón, E., Szantó, M., Pacheco, F., Contreras, E., \& Galves, A. (2016). Guía general para la gestión de residuos sólidos domiciliarios. https://www.cepal.org/sites/default/files/ publication/files/40407/S1500804_es.pdf

UIS, U. I. de S. (2010). Implementación de Plan de Gestión Integral de Residuos Solidos en la Universidad Industrial de Santander. https://www.uis.edu.co/ webUIS/es/gestionAmbiental/documentos/ capacitaciones/Capacitacion PGIR Sedes. pdf

Bailey, A. E. (2001). Industrial Oil and fat products, second edition(Segunda ed.). España: REVERTE S.A. Obtenido de https://books.google.com.co/boo ks? hl=es \& $\mid r=\& i d=x F j G D C m L u K Q C$ \&oi=fnd \&pg $=P A 3 \& d q=D E F I N A+A C$ EITE + \&ots $=$ HzMFIS1WO3\&sig $=$ DGa9kmSIISp2vKns1U7dxMiQs\&redir esc $=y \# v=$ onepage $\& q=D E F I N A \% 20$ ACEITE\&f=false
BUNGE. (n.d.). Aceites Vegetales. Pagina Web . Retrieved March 13, 2021, from https:// es.bungenorthamerica.com/products/ categories/96-aceites-vegetales

AMORÓS, G. D. (2017). Razones de los administradores de los administradores de lima, para no reciclar aceite vegetal usado. Universidad de San Ignacio de Loyola. Obtenido de http:// repositorio.usil.edu.pe/handle/ USIL/2752

Villabona A, Iriarte R, Tejada C. n.d. "Alternativas Para El Aprovechamiento Integral de Residuos Grasos de Procesos de Fritura - Dialnet." Retrieved February 27, 2021 (https://dialnet.unirioja.es/servlet/ articulo?codigo $=6382715)$.

Juárez, M. D., \& Sammán, N. (2007). El deterioro de los aceites durante la fritura - Dialnet.

Pons, G. A. (2015). Aceites vegetales, hacia una producción sostenible. El Hombre y La Maquina, 46, 9-19. https://www.redalyc. org/pdf/478/47843368002.pdf

Ayala, M. J. (2011). evaluación de la calidad del aceite de mezclas vegetales utilizado en doce frituras sucesivas empleado para freír plátano hartón. 17. Obtenido de http:// hdl.handle.net/10554/8796

BUNGE. (n.d.). Aceites Vegetales. Pagina Web . Retrieved March 13, 2021, from https:// es.bungenorthamerica.com/products/ categories/96-aceites-vegetales

CECAN CORPORACION. (n.d.). Biopravu Corporación CECAN. Retrieved March 13, 2021, from https://corporacioncecan.org/ biopravu/ 
Gobierno de La Rioja. (2016). Aceite usado de origen doméstico. Residuos Con Gestión Especial . https://www.larioja.org/medioambiente/es/residuos/residuos-gestionespecial/aceite-usado-origen-domestico

BIOGRAS. (2018). BIOGRAS S.A.S - Aceite Vegetal Usado. Pagina Web. https:// biogras.com.co/avu/aceite-vegetal-usado/

Wisman, D. P. (n.d.).(2018) iNo lo tires! Opinion Caribe. Retrieved February 27, 2021, from https://www.opinioncaribe. com/2018/10/10/no-lo-tires/

Solarte Burbano, N., \& Vargas Doraro, M. C. (2013). Diseño de las estrategias de recolección del aceite de cocina usado para su reutilización en la producción de biodiesel en 4 barrios de la ciudad de Cali. Instname:Universidad Autónoma de Occidente. http://red.uao.edu.co// handle/10614/5196

UIS, U. I. de S. (2010). Implementación de Plan de Gestión Integral de Residuos Solidos en la Universidad Industrial de Santander. https://www.uis.edu.co/ webUIS/es/gestionAmbiental/documentos/ capacitaciones/Capacitacion PGIR Sedes. pdf

Rondón, E., Szantó, M., Pacheco, F., Contreras, E., \& Galves, A. (2016). Guía general para la gestión de residuos sólidos domiciliarios.https://www.cepal.org/ sites/default/files/publication/files/40407/ S1500804_es.pdf

UIS, U. I. de S. (2010). Implementación de Plan de Gestión Integral de Residuos Solidos en la Universidad Industrial de Santander. https://www.uis.edu.co/ webUIS/es/gestionAmbiental/documentos/ capacitaciones/Capacitacion PGIR Sedes. pdf
Ángel, M. S. (2018). estudio de viabilidad ambiental y económica del aprovechamiento del aceite vegetal usado proveniente de cocina comerciales del centro de Villavicencio como insumo para la elaboración de biodisel en el Meta. Recuperado de: UNIVERSIDAD SANTO TOMAS DE VILLAVICENCIO. https://repository.usta.edu.co/bitstream/ handle/11634/14196/2018miguelmend ez.pdf?seque

ASOGRASAS. (2016). Ministerio de ambiente reglamenta disposición de aceites de cocina usados en el país. Recuperado de https://www.minambiente.gov.co/ index.php/noticias-minambiente/3673ministerio-de-ambiente-reglamentadisposicion-de-aceites-de-cocinausados-en-el-pais

Catalán3, S. D. (14 de 04 de 2015). Aceites vegetales de uso frecuente en Sudamérica: características y Propiedades. NUTRICION HOSPITALARIA, 1119.https://doi. org/10.3305/nh.2015.32.1.8874

complexity, O. O. (2019). Mayores Exportadores de Jabón Recuperado el 2019, de https://oec.world/es/profile/sitc/554 1/

Fedebiocombustible. (2019). precios Biodiesel 2019 Obtenido de

https://www.fedebiocombustibles.com/ estadística-precios-titulo Biodiesel.htm

Guamán, D. A. (2017). EXPORTACION DE JABON DE TOCADOR ARTESANAL A PORTUGAL. UDLA. Obtenido de http:// dspace.udla.edu.ec/handle/33000/7343 
Mar Marañón, Irequi, Domenech, Fernández, González. (abril, mayo, junio de 2008). Revista académica editada y mantenida por el grupo EUMED.NET de la Universidad de Malaga (4), 8. doi:1988-2483

Maza, C. L. (2007). Evaluación de impactos ambientales. Universidad de Chile, 579. Recuperado el 20 de 01 de 2020, de http://repositorio.uchile.cl/bitstrea $\mathrm{m} /$ handle/2250/120397/Evaluacion _de_Impactos_Ambientales.pdf?se quence $=1$ \&isAllowed $=y$

MinAmbiente. (2017). DOCUMENTO DE SOPORTE TÉCNICO PRELIMINAR. Bogotá. obtenido de http://www.andi. com.co/Uploads/Documento $\% 20$ Soporte\%20Tecnico \%20ACU\%20 -Ajustes\%20-29-09- 17.pdf

Molina, A. M. (2012). Plan de negocio para la producción y comercialización de jabón líquido de tocador a partir de residuos de aceite usado de cocina. UNIVERSIDAD DE LOS ANDES. Obtenido de. https:// repositorio.uniandes.edu.co/bitstream/ handle/1992/14986

P Albarracín, F. G. (2010). Estudios de caracterización de aceites usados en frituras para ser utilizados en la obtención de jabón. Universidad Nacional de Tucumán (32). Obtenido de https://www.researchgate.net/ publication/236671175_Estudios_de_ Caracterizacion_de_Aceites_Usados_ en_Frituras_para_ser_Utilizados_en_ la_Obtencion_de_Jabon
Paucar-Menacho, Luz María, Salvador-Reyes, Rebeca, Guillén-Sánchez, Jhoseline, Capa-Robles, Juan, \& Moreno-Rojo, Cesar. (2015). Estudio comparativo de las características fisicoquímicas del aceite de sacha inchi (Plukenetia volubilis I.), aceite de oliva (Olea europaea) y aceite crudo de pescado. Scientia Agropecuaria, 6(4), 279290. https://dx.doi.org/10.17268/sci. agropecu.2015.04.05

RAMÍREZ HERNÁNDEZ, O. (2015). Identificación de problemáticas ambientales en Colombia a partir de la percepción social de estudiantes universitarios localizados en diferentes zonas del país. Revista internacional de contaminación ambiental. doi:01884999

Regla, I. (01 de 05 de 2014). LA QUÍMICA DEL JABÓN Y ALGUNAS APLICACIONES. Revista digital universitaria, 15(5). Obtenido de http://www.revista.unam. $\mathrm{mx} / \mathrm{vol} .15$ /num1/art03/

SALAS, C. V. (2009). La elaboracion de jabón como método de trabajar la coeducación en los centros escolares. Obtenido de https://archivos.csif.es/archivos/ an dalucia/ensenanza/revistas/csicsif/r evista/pdf/Numero_17/CARLOS_ VAZQUEZ_SALAS_1.pdf

Subdirección de Medio Ambiente. (s.f.). COMO FABRICAR JABÓN CASERO CON ACEITE USADO. Obtenido de http:// www.munistgo.info/medioa mbiente/ wpcontent/uploads/2016/10/Como_ fabricar_jab\%C3\%B3n_casero_recicl ando_aceite_usado.pdf 